\title{
Invariant scaling relationships and their possible application in predicting radionuclide uptake in plants
}

\author{
K.A. Higley and D.P. Bytwerk \\ Department of Nuclear Engineering \& Radiation Health Physics, Oregon State University, \\ Corvallis, OR 97331, USA
}

\begin{abstract}
Scaling factors, used to predict radionuclide uptake as a function of mass, have tremendous potential to provide a more transparent approach to risk assessment. Although the historical literature might seem to offer a wealth of data for the purposes of testing these scaling relationships, a more defensible alternative may be to conduct new site-specific data collection efforts. Trace element analysis was conducted on 16 plant species from a single location in Oregon. Results for ten elements and six species exhibit mass dependence on trace-element uptake. Transfer factors calculated for several elements spanned only an order of magnitude across all plant species. Conversely, radionuclide data taken from the open literature was inconclusive in the analysis for mass effects.
\end{abstract}

\section{INTRODUCTION}

Bioconcentration, or transfer factors (TF) are an integral part of both human and ecologic radiological risk assessments. Typically they are used to predict uptake of a radiocontaminant from an abiotic component of the environment to a biotic component. Historically, they have been empirically obtained through field or laboratory studies, or estimated by extrapolation from the behavior of chemical analogues. Transfer factor data exist for several radionuclides in selected environments, but the emphasis is largely on plants of economic or cultural interest. Values can range over orders of magnitude for a single radionuclide [1]. The data sets for plant species tend to be restricted to those significant to the human food chain, and for which measurements can be readily obtained with reasonable cost and time constraints. If methods could be developed to estimate technically defensible TFs across a wide range of environments and species this would represent a considerable enhancement in current methods of radiological risk assessment.

\section{BACKGROUND}

Transfer Factors have been both the product and tool used to assess radionuclide uptake in biota. There have been attempts to better understand underlying mechanisms responsible for radionuclide uptake, and therefore explain, and predict TFs, but the results have been less than satisfactory except on a limited basis (e.g., [2-7]. There have been attempts at alternative analysis - particularly by taxa [6] however the data were extracted from multiple sites, with varying soil chemistry, potentially obscuring the results. In all cases, the development of a simple, but broadly predictive tool has not emerged.

At the same time, outside the world of radioecology, there has been considerable research on application of scaling functions as a tool for understanding a broad swath of mechanisms and traits in both plants and animals. There are several allometric equations that relate animal body size to many parameters, including ingestion rate, life span, inhalation rate, home range and more [8]. The most common form of allometric equation is the power function:

$$
\mathrm{Y}=\alpha \mathrm{X}^{\beta}
$$

where $\mathrm{Y}$ and $\mathrm{X}$ are size related measures, and $\alpha$ and $\beta$ are constants. These functions have also been applied to plants, and are generally accepted [9-14]. Parameters that have been examined specifically for plants include annualized biomass production (which scales as mass, $M$, to the $3 / 4$ power) and plant 
body length $\mathrm{L}$, which purportedly scales as $\mathrm{M}^{1 / 4}$, although there is some controversy for metabolism, size and nitrogen content $[15,16]$. There have been noted distinctions between plant types in regard to the scaling exponent - for example isometric scaling, $\mathbf{M}^{1}$ for non woody and $\mathrm{M}^{3 / 4}$ for woody plants for selected parameters [14]. However, there is considerable discussion on the nature and value of the exponent [15]. Studies have also been done on interspecific trends in leaf nitrogen and phosphorus [14] and in $\mathrm{Sr} / \mathrm{Ca}$ and $\mathrm{Ba} / \mathrm{Ca}$ partitioning in trophic chains [17]. Significantly, one area that does not appear to have been investigated to any great extent, is the use of allometric functions in the uptake of trace, or ultratrace constituents such as radionuclides in plants.

\section{METHODS}

Two approaches were taken by the authors test for scaling relationships in plants. The first was based on mining the existing radioecology literature, and the second was to conduct a localized, but speciesintensive, sampling and analysis effort.

\subsection{Literature review for ${ }^{137} \mathrm{Cs},{ }^{90} \mathrm{Sr}$, and ${ }^{239} \mathrm{Pu}$}

The initial approach was to test scaling functions against tabulated radionuclide transfer factors (TFs) reported in the open literature from a variety of locales. Data sets were selected where information was available for multiple species grown on the same site. This was done to provide a variety of species (and masses) to test the scaling concepts, and rule out the effect of site-specific chemistry on uptake. Reports from locations in the United States, Bangladesh, Australia, Taiwan and Japan [18-24] were selected. Radionuclide-specifc TFs were normalized at each site on a scale of $0-1$ for all plant species tested at each locale. The purpose of normalization was to remove, as much as possible, the influence of site chemical characteristics (others [2] have noted many of the complexities that complicate the determination of TFs).

TFs were tested against total dry mass $(\mathrm{kg})$, annualized growth rates $(\mathrm{kg} / \mathrm{plant} / \mathrm{yr})$, and plant height $(\mathrm{m})$. These parameters were selected because allometric relationships have been demonstrated for each. Literature values of TFs for ${ }^{137} \mathrm{Cs},{ }^{90} \mathrm{Sr}$, and ${ }^{239} \mathrm{Pu}$ for $\sim 40$ plant species were evaluated. These nuclides were chosen because of the presumed greater abundance of data, and because they encompassed elements that ranged from essential to insignificant in their biological importance. Plants examined included common vegetable crops, grains, fruits, trees, shrubs, and grasses. Some of the specific species included rice (presumed to be Oryza sativa L.), peanuts (presumed to be groundnut, Arachis hypogaea L.), pineapple (presumed to be Ananas comosus), cabbage (presumed to be Brassica oleracea var. capitata L.), tomato (presumed to be (Lycopersicum esculentum Mill), spinach (presumed to be Indian spinach (Basella rubra - L.), grass (presumed to be Triticale (X Triticosecale Wittmack), okra (Abelmoschus escelentus, var. Clemson spineless), sweet corn (Zea mays var. silver queen), lettuce (Lactuca sativa var. earl butterhead), turnips (Brassica rap var. white-globe), beans (Phaseolus vulgaris), eggplant (Solanum melongena var. Burpee hybrid), cheatgrass (Bromus tectorum L.), peas (Pisum sativum, Var. Blue Bonnet), barley (Hordum vulgare, var. U. Cal. Briggs), alfalfa (Medicago sativa, var. Ranger), willow (Salix amygdaloides), sagebrush (Artemisia tridentata), Mung beans (Vigna radiata), Sorghum (presumed to be Sorghum bicolor); carrots (Daucus carota), and radishes (Raphanus sativus).

\subsection{Field investigation into trace element concentrations}

The second approach taken to was to extensively sample a single geographic location, selecting multiple species which spanned a wide range of masses. In this instance the authors utilized the Oregon State University research forest. McDonald-Dunn is a teaching and research forest on the western edge of the Willamette Valley adjacent to Oregon State University near Corvallis, OR, USA. It is on the 
eastern foothills of the Oregon Coast Range, and lies within a transition zone between them and the Willamette Valley. The forest covers approximately 4.45154 ha and contains old-growth as well as logged forest sections. The section that was sampled as part of this study consisted of a coniferous overstory of Douglas-fir (Pseudotsuga menziesii) with western red cedar (Thuja plicata) and western hemlock (Tsuga heterophylla) forming the understory. The tall shrub layer contained vine maple (Acer circinatum) and ocean spray (Holdiscus discolor) and the herb layer had salal (Gaultheria shallon), oregon grape (Mahonia nervosa) and western sword fern (Polystichum munitum).

A total of 50 plants (Table 1) from more than 16 species were collected. Samples were harvested as either total plant, or divided into above and belowground (root) sections, for a total of 91 samples. Mineral soil and forest duff layers were also collected from the location. Plants were cleaned and roots were washed to remove mineral matter. Wet weights were recorded for all vegetation samples, and then they were dried to a constant weight at $55^{\circ} \mathrm{C}$. Plants were ground, homogenized, and then subaliquouts taken for analysis. Dry weights ranged from: $0.049 \mathrm{~g}$ for an entire Viola glabella to $1.64 \mathrm{~kg}$ for an aboveground section of Acer circinatum. Samples were subjected to neutron activation using the Oregon State TRIGA reactor (OSTR). Gamma spectral analysis was performed on a subsample of the plant species shown in Table 1; other analyses are pending. Reference standards (from the National Institute of Standards \& Technology) were used to calculate element concentrations in the plant and soil samples. Transfer factors were calculated as the ratio of plant elemental concentration to soil elemental concentration. The data included in this report are for ten elements, but other results will be forthcoming.

Table 1. Species collected in the McDonald/Dunn Research Forest and the elements presented in this paper.

\begin{tabular}{|c|c|c|c|c|c|c|c|c|c|c|}
\hline \multirow[b]{2}{*}{ Species Sampled } & \multicolumn{10}{|c|}{ Trace elements analyzed } \\
\hline & $\mathrm{Na}$ & $\overline{\mathrm{K}}$ & Sc & $\mathrm{Fe}$ & $\mathrm{Co}$ & $\mathrm{Zn}$ & $\mathrm{Br}$ & $\overline{\mathrm{Rb}}$ & $\mathrm{La}$ & $\mathrm{Sm}$ \\
\hline $\begin{array}{l}\text { Goodyera oblongifolia - Rattlesnake Plantain } \\
\text { Orchid }\end{array}$ & $\bullet$ & $\bullet$ & $\bullet$ & $\bullet$ & $\bullet$ & $\bullet$ & $\bullet$ & $\bullet$ & $\bullet$ & $\bullet$ \\
\hline Viola glabella - Pioneer Violet, Stream Violet & $\bullet$ & $\bullet$ & $\bullet$ & $\bullet$ & $\bullet$ & $\bullet$ & $\bullet$ & $\bullet$ & $\bullet$ & $\bullet$ \\
\hline Gaultheria shallon - Salal & $\bullet$ & $\bullet$ & $\bullet$ & $\bullet$ & $\bullet$ & $\bullet$ & $\bullet$ & $\bullet$ & $\bullet$ & $\bullet$ \\
\hline $\begin{array}{l}\text { Osmorhiza chilensis (syn: Osmorhiza berteroi) - } \\
\text { Mountain Sweet Cicely }\end{array}$ & $\bullet$ & $\bullet$ & $\bullet$ & $\bullet$ & $\bullet$ & $\bullet$ & $\bullet$ & $\bullet$ & $\bullet$ & $\bullet$ \\
\hline $\begin{array}{l}\text { Mahonia nervosa - dwarf Oregon grape (formerly } \\
\text { Berberis sp.) }\end{array}$ & $\bullet$ & $\bullet$ & $\bullet$ & $\bullet$ & $\bullet$ & $\bullet$ & $\bullet$ & $\bullet$ & $\bullet$ & $\bullet$ \\
\hline Polystichum munitum - Western Sword Fern & $\bullet$ & $\bullet$ & $\bullet$ & • & $\bullet$ & $\bullet$ & $\bullet$ & $\bullet$ & $\bullet$ & $\bullet$ \\
\hline Symphoricarpos mollis - creeping snowberry & o & o & o & o & o & 0 & o & o & ○ & o \\
\hline Wahlbergella montana - Whipplea & o & o & o & O & o & o & o & o & o & o \\
\hline Abies amabalis - Pacific silver fir & o & $\circ$ & o & o & o & o & o & o & $\circ$ & o \\
\hline Achlys triphylla - vanilla leaf & 0 & 0 & 0 & 0 & 0 & 0 & 0 & 0 & 0 & 0 \\
\hline Holodiscus discolor - ocean-spray & $\circ$ & $\circ$ & $\circ$ & 0 & 0 & 0 & 0 & $\circ$ & $\circ$ & 0 \\
\hline Acer circinatum - vine maple & 0 & o & O & $\circ$ & o & O & o & $\circ$ & $\circ$ & o \\
\hline Tsuga heterophylla - western hemlock & o & ○ & O & o & o & o & o & O & o & o \\
\hline Pseudotsuga menziesii - Douglas-fir & o & o & o & o & o & o & o & o & o & O \\
\hline Cornus nuttallii - Pacific Dogwood & o & o & o & o & o & o & o & o & o & 0 \\
\hline Mineral Soil & 0 & o & o & o & o & o & o & $\circ$ & ○ & o \\
\hline Litter (forest floor duff) & o & o & 0 & o & 0 & o & o & $\circ$ & $\circ$ & 0 \\
\hline
\end{tabular}

$\bullet=$ results included

$\circ=$ results pending

\section{RESULTS AND DISCUSSION}

\subsection{Literature analysis for ${ }^{137} \mathrm{Cs},{ }^{90} \mathrm{Sr}$, and ${ }^{239} \mathrm{Pu}$}

In the course of this research it became apparent that the methodology used to calculate (and ultimately report) TFs frequently omits information useful to the testing of allometric functions. 
For example - total dry biomass of plants, or plant parts, is rarely included in the literature. Therefore it had to be estimated from other sources $[3,25]$. Several reports only referred to common plant names (e.g., 'grass' or 'carrots'), making it impossible to identify species. As a result, while the limited data suggested mass effects on radionuclide uptake for these nuclides, none of the results were statistically significant.

\subsection{Field investigation into trace element concentrations}

The measured concentrations for selected elements as a function of total plant mass are shown in Figure 1. Trendlines and correlation coefficients are shown for each element. The data set is admittedly small, but there is an observable mass effect. The element with the highest observed plant concentration, $\mathrm{K}$, is a primary macronutrient in plants, and has been shown elsewhere to scale with mass [14]. Rubidium, which is chemically similar to $\mathrm{K}$, has a similar slope. Zinc is a plant micronutrient, required normally in small amounts. Cobalt and La also exhibit mass effects, but to a lesser extent.

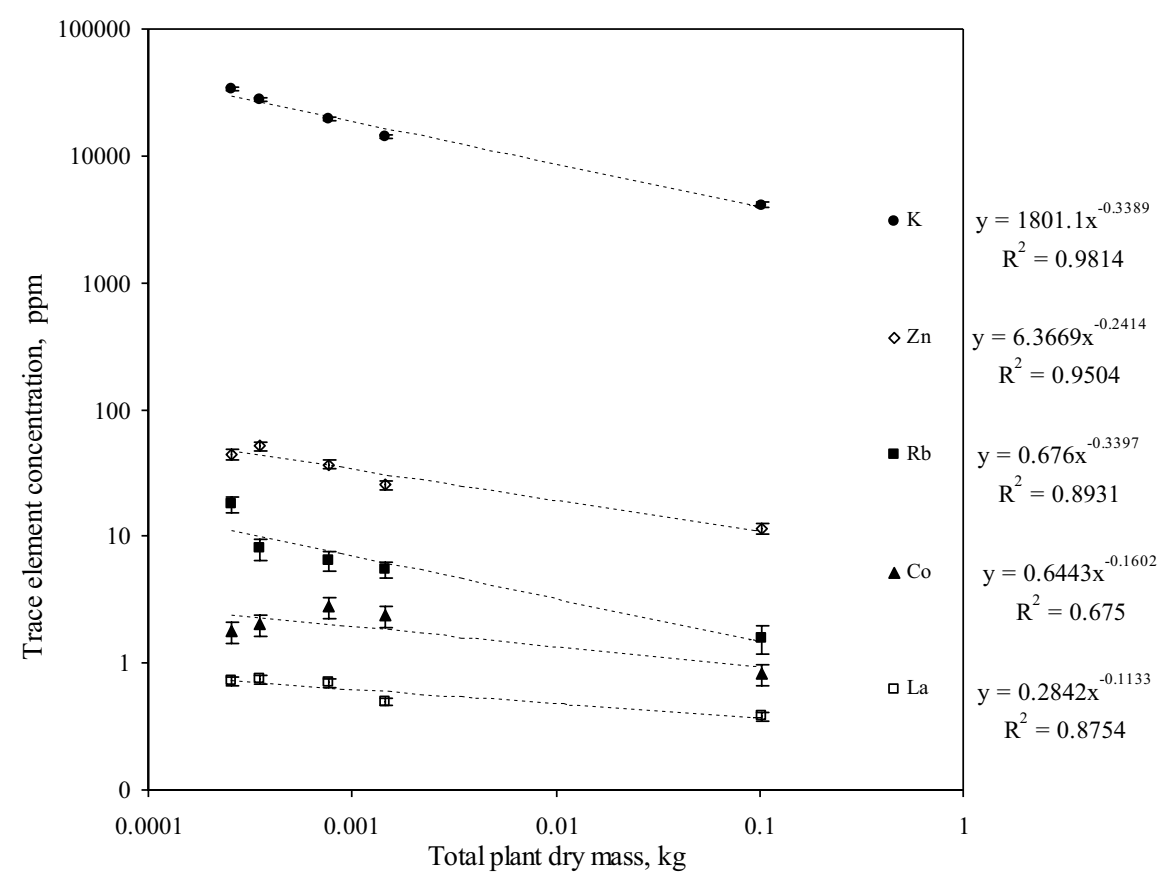

Figure 1. Concentrations for selected trace elements in plant samples collected in the OSU McDonald/Dunn Research Forest. The calculated best fit function for each data set is at right. Data are for total plant mass $\pm 1 \sigma$ concentration.

Element-specific transfer factors calculated for each sample are provided in Figure 2. The data are distinguished as "total plant", "above-ground" and "root" mass. Several elements appear to exhibit lower TFs for the above-ground portion of the plant. It is not clear if this distinction is a consequence of preferential distribution of the trace elements within the plant, or the possibility of residual soil adhering to the root portion (although all roots were repeatedly washed prior to drying and analysis). It appears that TFs for "total plant" or "above-ground" samples span only about an order of magnitude for many elements. 


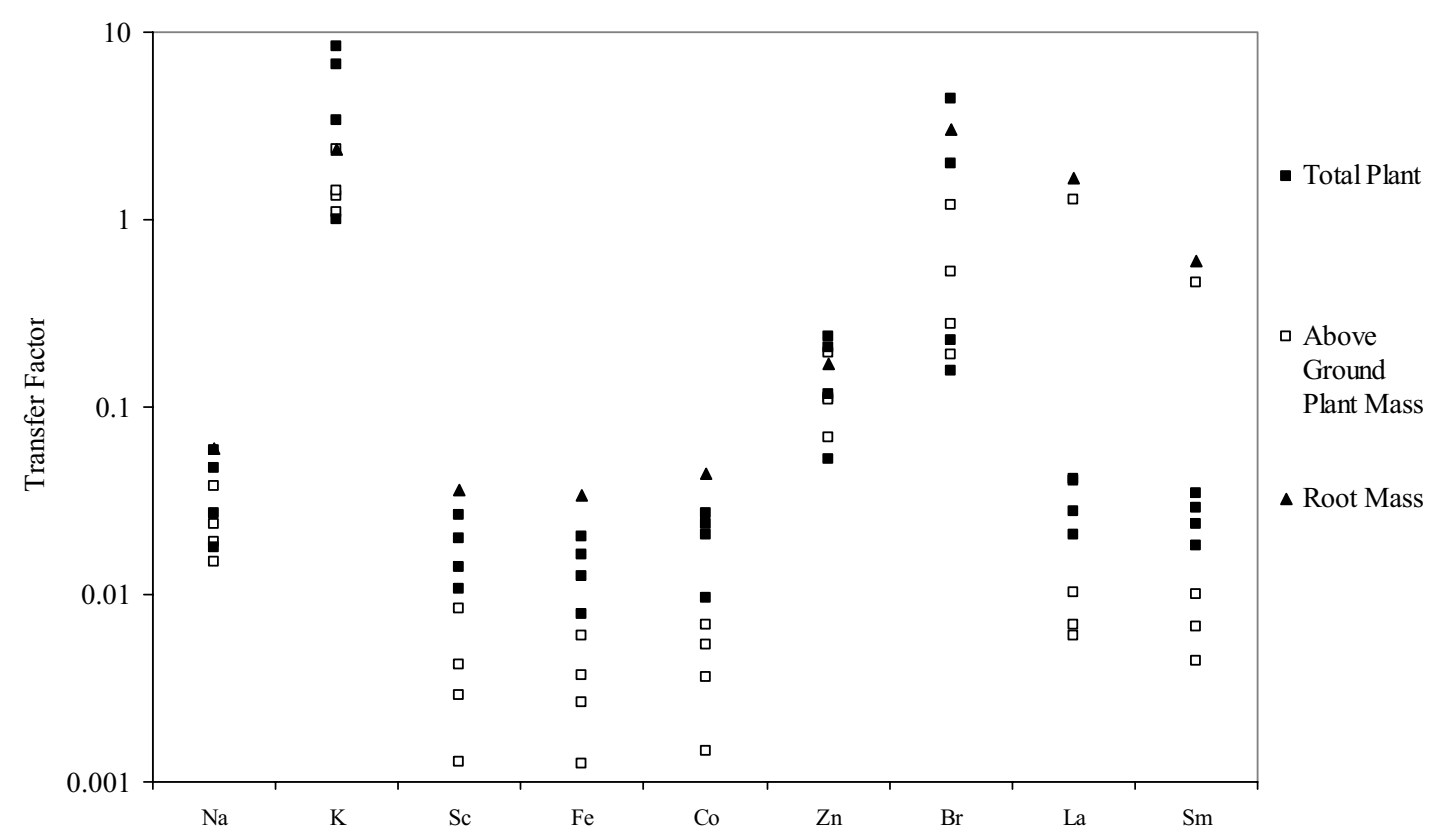

Figure 2. Transfer factors for plant samples collected in the OSU McDonald/Dunn Research Forest. Data are shown for samples collected as total plant, root mass, and above-ground plant mass.

\section{CONCLUSIONS AND RECOMMENDATIONS}

This work is part of an ongoing analysis, and consequently the results are preliminary. In the course of this research it became apparent that "mining" the technical literature as a means to assess mass effects on radionuclide uptake is fraught with difficulties. Issues such as explicit identification of species, total plant mass, and multiple soil types all combine to restrict the utility of reaching back into the literature. One alternative method undertaken here was measurement of stable element concentrations in multiple plant species (spanning a wide range in mass), and taken from the same location. The results shown in this paper are only for small plant species, with data for the larger trees and shrub still pending. Even with these limitations, the data suggest that mass effects do exist. Data collection and analysis will continue at this research site, and hopefully will be extended into other environments.

If, with further analysis, the mass effects are not statistically robust (or if the scaling is isometric), the multiple species analysis from a single site may still hold some utility. It may be possible to bracket expected TFs for a site (as suggested in Figure 2). If the scaling results $\underline{d o}$ show robustness, then there are larger questions to be addressed: how to translate from stable elements concentrations, which presumably represent equilibrium situations, to that of radionuclides released into an environment as a consequence of planned or accidental situations. There are tremendous potential benefits to the use of scaling functions. These include the ability to extrapolate beyond the type of data (e.g., primarily foodstuffs) previously collected, and more importantly, the overall transparency provided use of such functions.

\section{Acknowledgments}

The authors wish to acknowledge the OSU College of Forestry for the use of the MacDonald/Dunn Research Forest and the OSU Radiation Center for use of the TRIGA Reactor. They also wish to thank Becky Fasth, Leah Minc, Nathan Knapp, and Tristan Hay for sample collection, preparation, and analysis. 
This research is based on work supported by the U. S. Department of Energy, under Cooperative Agreement Number DE-FC01-06EW07053 entitled 'The Consortium for Risk Evaluation with Stakeholder Participation III' awarded to Oregon State University. The opinions, findings, conclusions, or recommendations expressed herein are those of the author(s) and do not necessarily represent the views of the Department of Energy or of Oregon State University.

\section{References}

[1] Napier, B., R. Fellows and K. Krupka, Soil-to-Plant Concentration Ratios for Assessing Food-Chain Pathways in Biosphere Models (NUREG/CR-6941). 2007, Pacific Northwest National Laboratory P.O. Box 999 Richland, WA 99352.

[2] Ehlken, S. and G. Kirchner, Journal of Environmental Radioactivity, 2002. 58(2-3): p. 97-112.

[3] Centofanti, T., et al., J Environ Qual, 2005. 34(6): p. 1972-1979.

[4] Maraziotis, E.A., Journal of Radiological Protection, 1992. 12: p. 77-84.

[5] Zhu, Y.G. and E. Smolders, Journal of Experimental Botany, 2000. 51(351): p. 1635-1645.

[6] Willey, N.J., S. Tang, and N.R. Watt,. J Environ Qual, 2005. 34(5): p. 1478-1489.

[7] Nisbet, A.F. and R.F.M. Woodman, Health Physics ; VOL. 78 ; ISSUE: 3 ; PBD: Mar 2000, 2000 : p. page(s) 279-288.

[8] West, G.B., Brown, J.H. and Enquist, B.J., Science, 1987. 276(122-126).

[9] Higley, K.A. and D.P. Bytwerk, Journal of Environmental Radioactivity, 2007. 98(1-2): p. 4-23.

[10] Beresford, N.A., et al., Journal of Radiological Protection, 2004. 24(4A): p. A89-A103.

[11] Niklas, K.J. and B.J. Enquist, Proceedings of the National Academy of Sciences of the United States of America, 2001. 98(5): p. 2922.

[12] Castelan-Estrada, M., P. Vivin, and J.P. GaudilllEre, L. Ann Bot, 2002. 89(4): p. 401-408.

[13] West, G.B. and J.H. Brown, Journal of Experimental Biology, 2005. 208(9): p. 1575-1592.

[14] Niklas, K.J., Ann Bot, 2006. 97(2): p. 155-163.

[15] Reich, P.B., et al., Nature, 2006. 439(7075): p. 457-461.

[16] Enquist, B.J., et al., in Nature. 2007, Nature Publishing Group. p. 218-222.

[17] Balter, V., Oecologia, 2004. 139(1): p. 83-88.

[18] Seel, J.F., F.W. Whicker, and D.C. Adriano, Health Physics, 1995. 68(6): p. 793-799.

[19] Whicker, F.W., et al., Journal of Environmental Radioactivity, 1999. 45(1): p. 1-12.

[20] Twining, J.R., T.E. Payne and T. Itakura, Journal of Environmental Radioactivity, 2004. 71(1): p. 71-87.

[21] Mollah A.S., B.A. and Ullah S.M., Radiation and Environmental Biophysics, 1998. 37(2): p. $125-128$

[22] Landeen, D.S. and R.M. Mitchell, Health Phys.; Vol/Issue: 6, 1986: p. Pages: 769-774.

[23] Yoshida, S. and Y. Muramatsu, Journal of Environmental Radioactivity, 1998. 41(2): p. 183-205.

[24] Chou, F.-I., et al., Journal of Environmental Radioactivity, 2005. 80(2): p. 175-181.

[25] Reddy, B.V.S., et al., Field Crops Research, 2003. 84(1-2): p. 57-77. 